\title{
New definitions of deformation index for the measurement of bus survival space in crash
}

DOI:

$10.1177 / 0954407018770541$

\section{Document Version}

Accepted author manuscript

Link to publication record in Manchester Research Explorer

\section{Citation for published version (APA):}

Abdul Hamid, I., \& Li, Q. M. (2018). New definitions of deformation index for the measurement of bus survival space in crash. Proceedings of the Institution of Mechanical Engineers, Part D: Journal of Automobile Engineering. https://doi.org/10.1177/0954407018770541

\section{Published in:}

Proceedings of the Institution of Mechanical Engineers, Part D: Journal of Automobile Engineering

\section{Citing this paper}

Please note that where the full-text provided on Manchester Research Explorer is the Author Accepted Manuscript or Proof version this may differ from the final Published version. If citing, it is advised that you check and use the publisher's definitive version.

\section{General rights}

Copyright and moral rights for the publications made accessible in the Research Explorer are retained by the authors and/or other copyright owners and it is a condition of accessing publications that users recognise and abide by the legal requirements associated with these rights.

\section{Takedown policy}

If you believe that this document breaches copyright please refer to the University of Manchester's Takedown Procedures [http://man.ac.uk/04Y6Bo] or contact uml.scholarlycommunications@manchester.ac.uk providing relevant details, so we can investigate your claim.

\section{OPEN ACCESS}




\title{
New definitions of deformation index
}

\section{for the measurement of bus survival space in crash}

\author{
A.H. Iskandar' ${ }^{1}$, Q.M. Li ${ }^{1 *}$ \\ ${ }^{1}$ School of Mechanical, Aerospace and Civil Engineering, The University of Manchester, Manchester M13 9PL, UK \\ * Corresponding author: email: qingming.li@ manchester.ac.uk
}

\begin{abstract}
Vehicle crashworthiness can be described as the capability of the vehicle to protect the occupant during a crash. The space containing the occupants should remain intact and does not allow any potential intrusion or crushing to injure the occupants. For rollover crash test of a bus, this safety space is well defined in a standard, i.e. the United Nations Regulation No. 66 (UN R66), where it gives pass/fail criteria. However, the standard does not measure and quantify the bus structural deformation. The measurement of such deformation has been systematically quantified by the Angular Deformation Index $\left(D I_{\alpha}\right)$, in which the deformation of bus structure can be generalized for comparative study giving more descriptive assessment of the bus structure deformation level. $D I_{\alpha}$ is suitable for rollover test that is done strictly in a controlled environment, where the deformation is typically not severe. In real crashes, impact load varies widely and can cause severe structural damages especially among the aged buses with poor structural strength, which are still broadly used in less developed countries. If the deformed bus structures penetrate deeply into the residual space, $D I_{\alpha}$ index become irrelevant because the angular values in the equation give exponential results. It is therefore suggested that a new deformation index, termed as the Area Deformation Index $\left(D I_{A}\right)$, is used for real rollover crashes involving severe damages to the bus structure. This is to quantify the damages in two dimensions once the structures penetrate into the residual space, up to where the structure is totally collapsed. By having this new index, a suitable structural deformation severity rating for the bus with respect to real rollover crashes can
\end{abstract}


be proposed. This severity rating can be correlated to the injury severity (e.g. number and level) of the bus occupants, and can be used to evaluate some specific parameters influencing crashworthiness performance (e.g. ageing effects). Case studies are discussed to show the practicality of the proposed $D I_{A}$ concept. Volume Deformation Index $\left(D I_{V}\right)$ is also proposed to quantify the deformation in three dimensions.

Keywords: Structural crashworthiness [vehicles], Structural deformation, aged bus, Area Deformation Index, survival space.

\section{Introduction}

Vehicle crashworthiness is a concept whereby the vehicle structure has the capability to protect the occupant during a crash. The vehicle space hosting occupants should remain intact without any intrusion or crushing to injure the occupants. This structural cage or 'protective cocoon', together with other design features, are intended to allow the impact energy to be absorbed by impact energy absorbers and by other designed energy management features in the vehicle [1]. Table 1 shows the summary of aged bus rollover cases involving fatalities and injuries in Malaysia [7]. It can be seen that there are high number of casualties due to rollover crashes and the figure is alarming. One of the main reasons for high fatality rate in rollover crash is the failure of bus structure when it collapses and intrudes deeply into survivable space of the bus. This is why for a bus rollover test, several international standards were made available to define and describe the survivable space, e.g. United Nations Regulation No. 66 (UN R66), Directive of European Commission 2001/85/EC, Australian Design Rule (ADR) 59/00, South Africa SANS 1563 and United States of America FMVSS 220 [2]. The aim of these standards is to make sure that the defined safety space within the bus is well protected by the superstructure of the bus during and after the roll-over crash. Safety space, or officially referred to as the 'residual space', is a space to be preserved in the passenger, 
driver and crew compartments to provide better survival possibility for them in a rollover accident [3], as shown in Figure 1.

Table 1 Summary of aged bus rollover cases involving fatalities and injuries in Malaysia, [7]

\begin{tabular}{|c|c|c|c|c|l|}
\hline Date & Case & $\begin{array}{c}\text { Age of bus } \\
\text { (years) }\end{array}$ & $\begin{array}{c}\text { Fatality } \\
(\mathbf{s})\end{array}$ & $\begin{array}{c}\text { Injury } \\
(\mathbf{s})\end{array}$ & \multicolumn{1}{|c|}{ Summary of the case } \\
\hline $09 / 03 / 07$ & $\begin{array}{c}\text { Kuala } \\
\text { Kangsar }\end{array}$ & 16 & 6 & 22 & $\begin{array}{l}\text { Bus hit side guardrail, slid the slope } \\
\text { and overturned }\end{array}$ \\
\hline $05 / 05 / 07$ & Cherating & 12 & 1 & 22 & $\begin{array}{l}\text { Bus hit side guardrail, slid the slope } \\
\text { and overturned }\end{array}$ \\
\hline $13 / 08 / 07$ & $\begin{array}{c}\text { Bukit } \\
\text { Gantang }\end{array}$ & 21 & 22 & 7 & $\begin{array}{l}\text { Bus hit side guardrail, slid the slope } \\
\text { and overturned }\end{array}$ \\
\hline $11 / 09 / 07$ & Baling & 15 & 7 & 34 & Bus hit embankment and overturned \\
\hline $06 / 01 / 08$ & Ipoh & 6 & 0 & 15 & $\begin{array}{l}\text { Brake failure and bus overturned on } \\
\text { the side of highway }\end{array}$ \\
\hline $12 / 06 / 08$ & Slim River & 13 & 1 & 23 & $\begin{array}{l}\text { Bus hit side guardrail, slid the slope } \\
\text { and overturned }\end{array}$ \\
\hline $26 / 02 / 08$ & Rembau & 6 & 0 & 6 & Bus hit guardrail and overturned \\
\hline $24 / 06 / 08$ & Behrang & 3 & 3 & 13 & Bus hit median and overturned \\
\hline
\end{tabular}




\section{Lateral arrangements}

a)

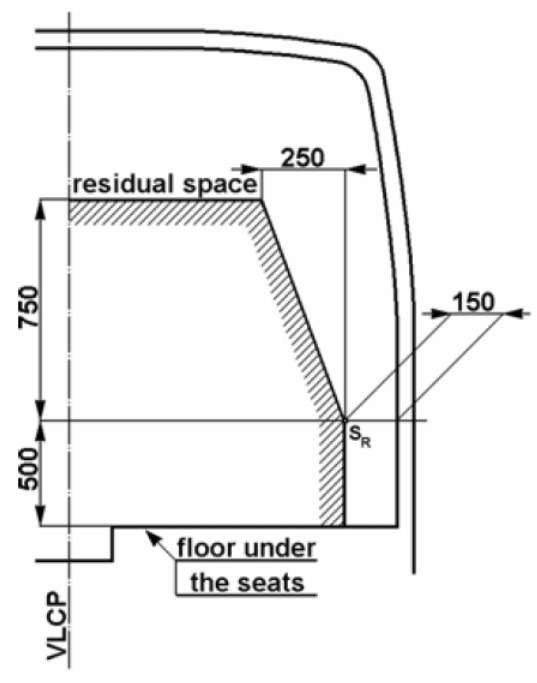

b)

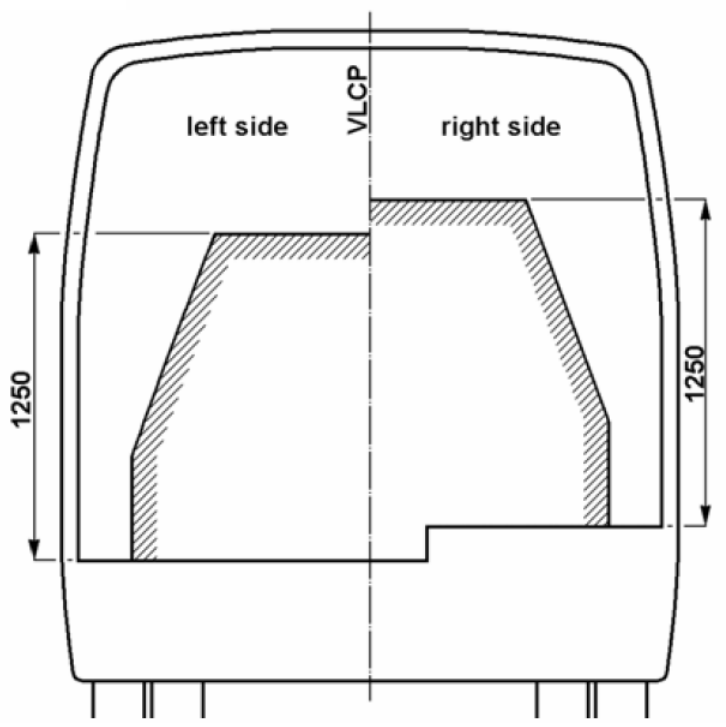

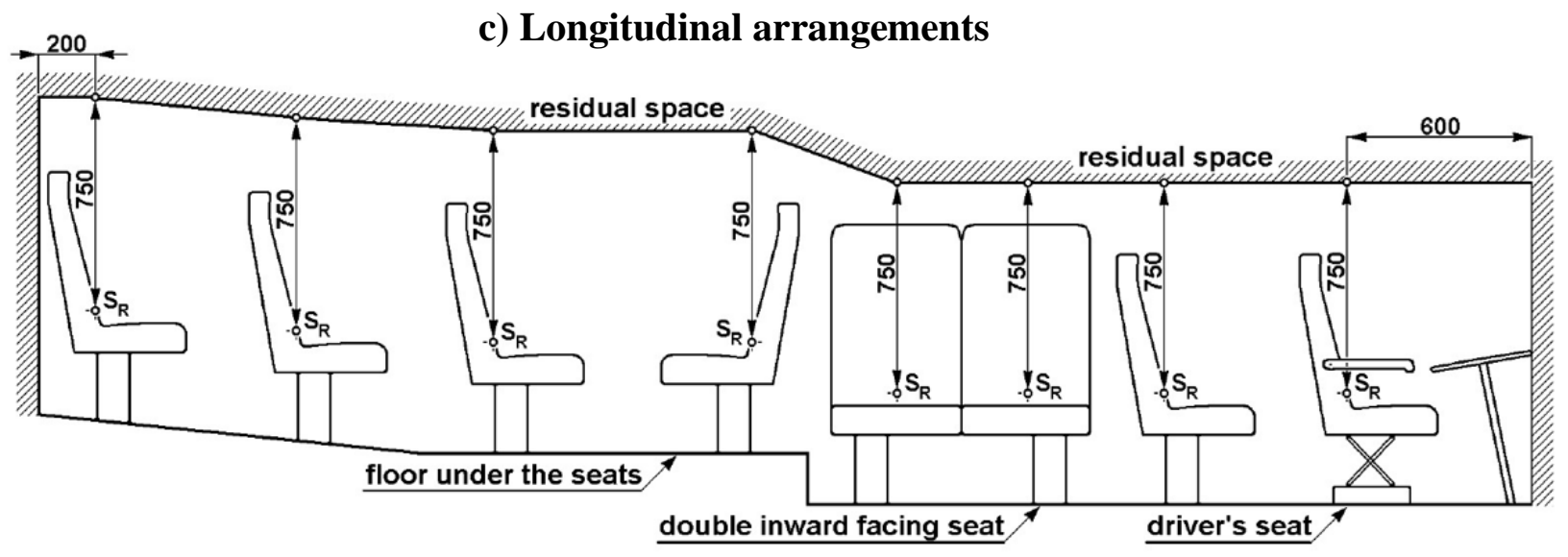

Figure 1 (a) \& (b) Lateral and (c) longitudinal arrangements of residual space (unit is in $\mathrm{mm}$ ), [3]

As defined in [3], "Superstructure" is the components of the bodywork which contains coherent parts and elements. The function of the bodywork is to bear loads. It has the strength and capability to absorb the energy and preserve the residual space during rollover. For consistency and simplicity, bus 'superstructure' term as used in the standard is referred to as the 'structure' in this paper. Parts of the bus structure are referred to as the frames i.e. upper frame, side frame and lower frame. 
Rollover test, as illustrated in Figure 2, is conducted to make sure the external parts of the bus like pillars, safety rings and luggage racks are not penetrating or intruding into the residual space. If penetration or intrusion has happened, then the tested bus will be considered as failed. Specification of the test is detailed out in Annex 5 of UN R66 standard [3]. It is worth to note that the rollover direction is not determined by the sides of the bus, i.e. off side (driver's side) or near side (the side next to the roadside). It is determined by how dangerous that side is to the preservation of the residual space. The determination of the direction of rollover test should consider factors such as the lateral eccentricity of the centre of gravity, the asymmetry of the residual space, and the asymmetrical constructional features of the two sides of the vehicle where the side of lesser support shall be chosen as the direction of the rollover test [3].

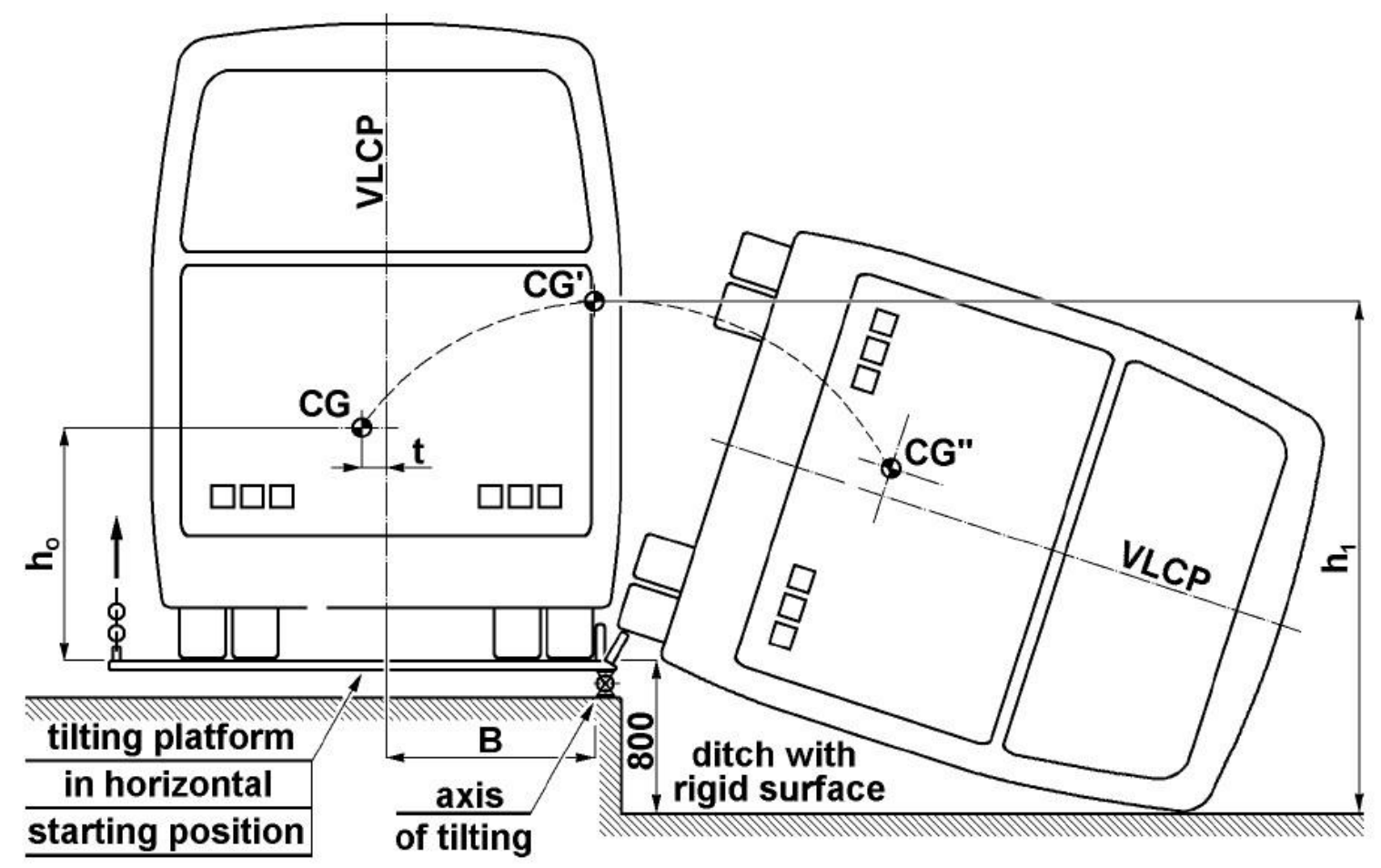

Figure 2 The path of the centre of gravity is shown through the starting and unstable equilibrium positions of the bus during rollover (unit is in $\mathrm{mm}$ ), [3]. 
In addition to the basic (full-scale) rollover test, four other approval methods are stated in [3], i.e. rollover test using body sections, quasi-static loading test of body sections, quasi-static calculation based on testing of components, and computer simulation of rollover test on complete vehicle. All these approved testing methods are intended for a new design of bus.

The dynamic nature of UN R66 approval procedure has been adopted by over 40 countries in the world as it closely resembles the real rollover crash. However, this procedure is expensive, time consuming and difficult to perform. To overcome these problems, variety of other assessment methods are suggested to improve bus structure. The ultimate aim is to protect the occupant survival space from being intruded by the structure, as well as to maximize the absorption of crash energy. For example, the Equivalent Rollover Testing (ERT) procedure was suggested as an alternative approval method, where bus structure components are being tested separately to simplify the complex deformation and energy distribution during a rollover test [4]. Different roof strength test was also suggested, like the roof crush test, to assess the strength of the bus structure by using finite element simulation [5].

As stated before, high fatality rate in real rollover crash in Malaysia is mostly due to bus structural failure. Besides other reasons, this failure is strongly influenced by ageing effects and noncompliance to the standards. In many cases investigated, the structural failures are well beyond the crash tests limit and deep intrude into the residual space. The recommended Angular Deformation Index $\left(D I_{\alpha}\right)$, which will be discussed further in this paper, is not suitable to measure this type of severe or even catastrophic failures. This is why a new deformation index is needed to measure different levels of failure which are happening in the real crashes, especially in the less developed countries.

This paper discusses the $D I_{\alpha}$ for the measurement of bus structural deformation during rollover test. It is followed by discussion on real rollover crashes investigated in Malaysia, factors 
contributing to its structural deformation severities and limitations of $D I_{\alpha}$ to measure severe deformations of real bus rollover crashes. A new concept of Area Deformation Index $D I_{A}$ is then introduced to measure the severe structural deformation of real bus rollover crashes, together with the structural deformation severity ratings. Some theoretical and real examples on how $D I_{A}$ can be used are discussed to show its practicality. Volume Deformation Index $\left(D I_{V}\right)$, which is the extension of $D I_{A}$ in three dimensions, is proposed to offer a more realistic measure of the severity of a bus roll-over crash.

\section{Angular Deformation Index}

Since the UN R66 only gives pass/fail criterion in the bus rollover test, it is necessary to measure and quantify the extent of the bus deformation. The measurement of such deformation can be systematically quantified, as shown by [2]. It is called the Deformation Index $(D I)$, in which the deformation of bus structure can be generalized for comparative study. It is a universal index to measure the extent of the deformation and the safety margin in the rollover case. Instead of giving only pass/fail criterion, Deformation Index gives more descriptive assessment of the bus structure deformation level in rollover tests. 

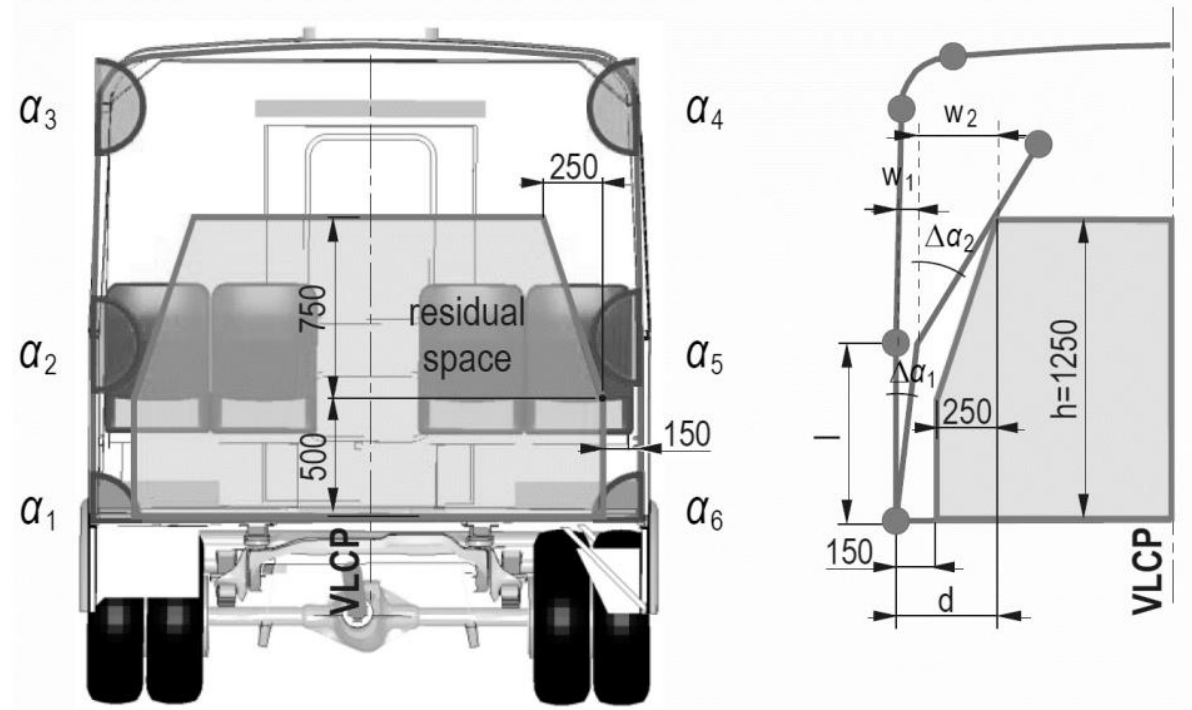

Figure 3 (a) Angles in the bus cross-section, and (b) geometry of the failure mode (unit is in mm), [2].

Figure 3 shows the cross-section of the bus. The VLCP stands for "Vertical Longitudinal Central Plane", i.e. the vertical plane which passes through the mid-points of the front axle track and the rear axle track [3]. The numbered angles are (i) $\alpha_{1}$ and $\alpha_{6}$ : wall to floor (WF) connections angles; (ii) $\alpha_{2}$ and $\alpha_{5}$ : waist rail (the structural part below the side windows) angles, and (iii) $\alpha_{3}$ and $\alpha_{4}$ : roof to wall (RF) connections angles.

The measurement of deformation utilized the change in angles as specified in Figure 3(b). The deformation index is based on the change of angles. Therefore, it can be called as the Angular Deformation Index $\left(D I_{\alpha}\right)$, which is a function of two major angles as shown in Eq. (1),

$$
D I_{\alpha}=f\left(\Delta \alpha_{1}, \Delta \alpha_{2}\right)
$$

$\Delta \alpha_{1}, \Delta \alpha_{2}$ are the changes of the angles due to the rollover impact deformation as shown in Figure 3(b).

From Figure 3(b), $w_{1}$ and $w_{2}$ are defined as

$$
\begin{gathered}
w_{1}=l \cdot \tan \left(\Delta \alpha_{1}\right) \\
w_{2}=(h-l) \cdot \tan \left(\Delta \alpha_{2}\right)
\end{gathered}
$$


The sum of $w_{1}$ and $w_{2}$ is equal to $\mathrm{d}$,

$$
w_{1}+w_{2}=d=150+250=400 \mathrm{~mm} \text { (for the bus shown in Fig.3) }
$$

The general expression is

$$
l \cdot \tan \left(\Delta \alpha_{1}\right)+(h-l) \cdot \tan \left(\Delta \alpha_{2}\right)=d
$$

or

$$
\frac{l}{d} \cdot \tan \left(\Delta \alpha_{1}\right)+\frac{(h-l)}{d} \cdot \tan \left(\Delta \alpha_{2}\right)=1
$$

Therefore, Angular Deformation Index can be defined as

$$
D I_{\alpha}=\frac{l}{d} \cdot \tan \left(\Delta \alpha_{1}\right)+\frac{(h-l)}{d} \cdot \tan \left(\Delta \alpha_{2}\right)
$$

With the above definition, it can be said that if $D I_{\alpha}$ is less than 1 , the bus passes the test. Otherwise, if it is equal to or larger than 1 , the bus fails the test. In [2], more levels of $D I_{\alpha}$ were proposed, as shown in Table 2.

Table 2 Rating ranges of angular deformation Index, $D I_{\alpha}[2]$

\begin{tabular}{lcc}
\hline Range & Descriptive strength rating & Star rating \\
\hline$D I_{\alpha}<0.4$ & strong & $* * * * *$ \\
\hline $0.4 \leq D I_{\alpha}<0.6$ & intermediate & $* * * *$ \\
\hline $0.6 \leq D I_{\alpha}<0.8$ & acceptable & $* * *$ \\
\hline $0.8 \leq D I_{\alpha}<1$ & poor & $* *$ \\
\hline$D I_{\alpha} \geq 1$ & inacceptable & $*$ \\
\hline \hline
\end{tabular}

Angular Deformation Index $\left(D I_{\alpha}\right)$ is very useful for the measurement of the structural deformation in a bus rollover test. The $D I_{\alpha}$ is suitable when the impact load applied during the test is controlled. In general, when $D I_{\alpha}$ is applied to new buses, the bus deformation in rollover tests is not severe because the bus structure has not been deteriorated. Therefore, $D I_{\alpha}$ is normally used to describe the structural crashworthiness levels of a bus between its baseline condition (original condition of the bus) and the critical condition when the bus structures touch the residual space. However, in real 
bus crashes, impact load is varying widely and can cause severe damage to the bus structure. If the bus structures deformed and penetrated deeply into the residual space, $D I_{\alpha}$ may no longer suitable. This is because the angular deformation index, which is a function of angles, becomes exponential if the angle values are too large.

The example of the change of $D I_{\alpha}$ value is shown in Figure 4 where graph of $D I_{\alpha}$ versus $\alpha_{1}$ is plotted when $\alpha_{2}$ is fixed to $0^{\circ}$. The $D I_{\alpha}-\alpha_{1}$ line is still linear when $\alpha_{1}$ is $18^{\circ}$ (and $D I_{\alpha}$ is 1.015 ), where the bus body structure was deformed and touched the lower and side sections of the residual space. However, the line increased exponentially when $\alpha_{1}$ is beyond $34^{\circ}\left(D I_{\alpha}=2.018\right)$. The same pattern occurred if $D I_{\alpha}$ versus $\alpha_{2}$ is plotted when $\alpha_{1}$ is fixed to $0^{\circ}$. The $D I_{\alpha}-\alpha_{2}$ line remains linear when $\alpha_{2}$ is $39^{\circ}$ (and $D I_{\alpha}$ is 0.935 ), where the bus body structure was deformed and touched the upper section of the residual space. However, the line increased exponentially when $\alpha_{2}$ is beyond $43^{\circ}\left(D I_{\alpha}=1.077\right)$. Note that the example is using bus model specified in [2], where $l=788 \mathrm{~mm}, d$ $=400 \mathrm{~mm}$ and $h=1250 \mathrm{~mm}$. Also, $\Delta \alpha_{2}$ in the given formula is a sum of $\alpha_{1}$ and $\alpha_{2}$ [2].

This example shows that for severe or catastrophic bus structural failure, $D I_{\alpha}$ is no longer applicable. This does not mean that the $D I_{\alpha}$ equation is wrong. It simply means that $D I_{\alpha}$ focuses on the measurement before the $D I_{\alpha}$ value reaches 1.0. Once the value is greater than 1.0, no matter what the value is, the bus has already failed. 


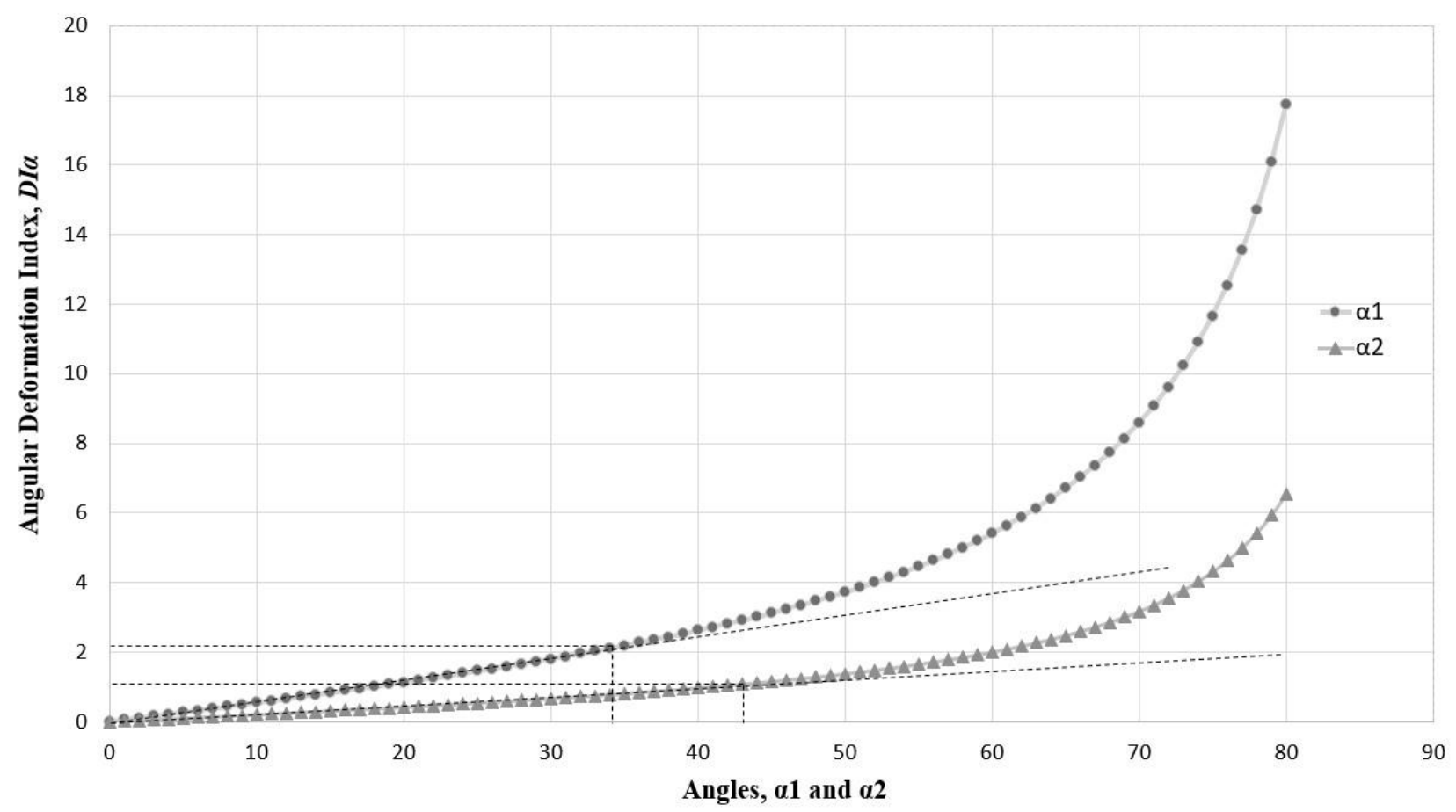

Figure 4 Angular Deformation Index versus deformation angles, $\alpha_{1}$ and $\alpha_{2}$

The above two conditions are presented in Figure 5 where the cross-sections of the bus structure and geometry of failure modes are shown. Figure 5(a) shows the original bus condition where all deformation angles are $0^{\circ}$ and $D I_{\alpha}=0.0$. In Figure 5(b), $\Delta \alpha_{1}=18^{\circ}$ and $\Delta \alpha_{2}$ is also $18^{\circ}$, which give $D I_{\alpha}=1.015$. In [2], this is described as basic failure mode I, where the plastic hinges developed at wall to floor (WF) and roof to wall (RW) and the structure touched the residual space. However, if $\Delta \alpha^{\prime}{ }_{1}=34^{\circ}$ and $\Delta \alpha^{\prime}{ }_{2}=34^{\circ}$ or more, $D I_{\alpha}$ is no longer linear as it increases exponentially. The same applied if condition in Figure 5(c) occur. If $\Delta \alpha_{1}=0^{\circ}$ and $\Delta \alpha_{2}$ is $39^{\circ}, D I_{\alpha}$ shall be 0.935. In [2], this is described as basic failure mode II where the plastic hinges developed at RF and at the waistrail level causing the structure to touch the upper section of residual space. If the structure failed to a level where $\Delta \alpha_{1}=0^{\circ}$ and $\Delta \alpha_{2}$ is $43^{\circ}$ or worse, $D I_{\alpha}$ will no longer be linear. 


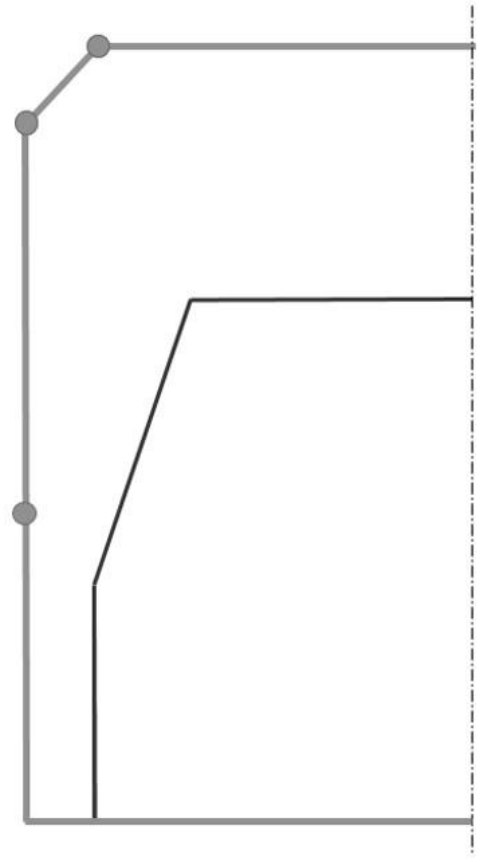

(a)

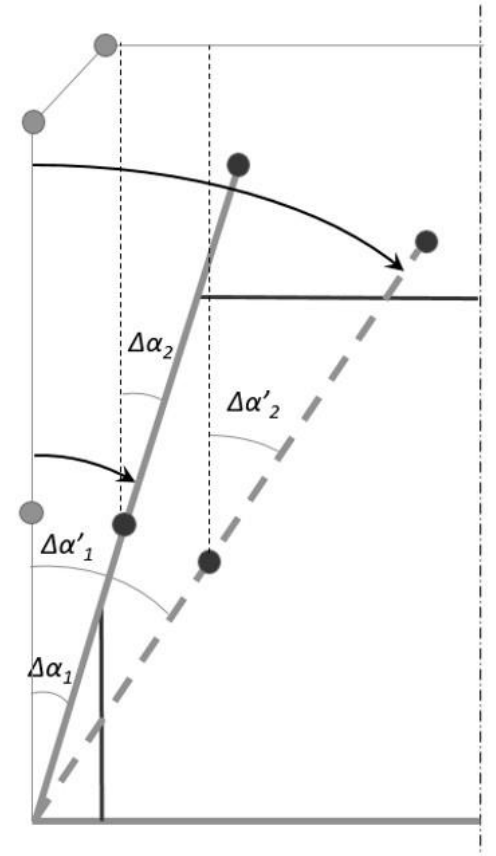

(b)

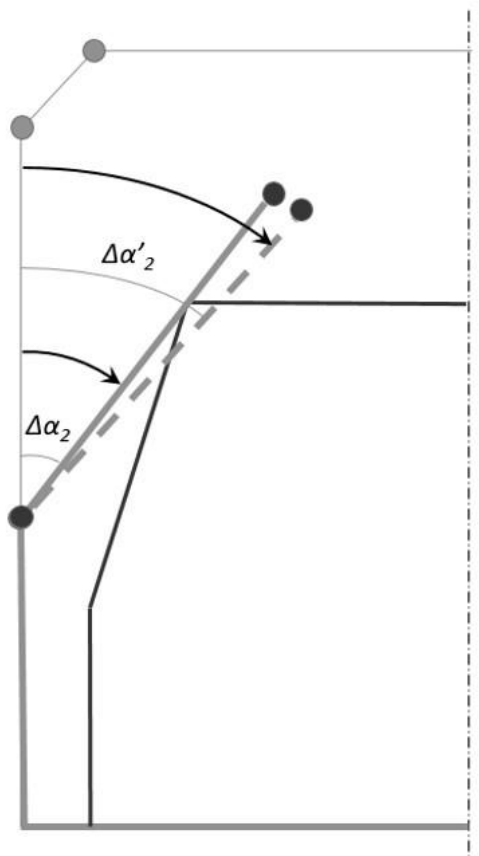

(c)

Figure 5 (a) $\Delta \alpha_{1}=0^{\circ}, \Delta \alpha_{2}=0^{\circ}, \Delta \alpha^{\prime}{ }_{1}=0^{\circ}, \Delta \alpha^{\prime}{ }_{2}=0^{\circ}, \quad$ (b) $\Delta \alpha_{1}=18^{\circ}, \Delta \alpha_{2}=18^{\circ}, \Delta \alpha^{\prime}{ }_{1}=34^{\circ}, \Delta \alpha^{\prime}{ }_{2}=34^{\circ}$, (c) $\Delta \alpha_{1}=0^{\circ}, \Delta \alpha_{2}=39^{\circ}, \Delta \alpha^{\prime}{ }_{1}=0^{\circ}, \Delta \alpha^{\prime}{ }_{2}=43^{\circ}$

The above failure modes are ideal where either $\Delta \alpha_{1}$ or $\Delta \alpha_{2}$ was set to zero. In practical, compound failure mode or failure mode III [2] is usually happened, where both $\Delta \alpha_{1}$ and $\Delta \alpha_{2}$ give some values. As it involve two variables, examples are not illustrated here to maintain simplicity.

Since the aim of this paper is to measure and quantify the severe and catastrophic deformations of bus structures especially in real crashes, a new definition of deformation index is required. This index should be sufficiently robust so that it can be used in a practical way for data collectors.

\section{Case Studies of Real Rollover Crashes}

Vehicle crashes involving public transportation, e.g. buses, trains etc. are highly sensitive and usually cause great public concerns as these accidents usually involve in multiple casualties. Indepth crash investigation is conducted to purposely find out the causes of the crash and recommendations are forwarded to relevant authorities and agencies. This is done with the aim to 
prevent the same kind of incident from repeating in the future, or to minimize the magnitude of casualties if the incident happens. Investigated cases are normally reported and recorded in the database in the form of indexes, coding of crash severities, analyses and write-ups. For example, the Collision Deformation Classification (CDC) coding is used to collectively record and represent the extent of real vehicle crash deformation. It is a seven-digit code developed by the federal US government for simple description of vehicle damage based on SAE J224 standard [6]. Abbreviated Injury Scale (AIS) is a coding to measure the injury severity due to road crashes [7]. For real bus rollover cases, damage extent of the bus structure can also be measured and coded so that the severity of structural deformation can be reviewed and analyzed in a systematic way.

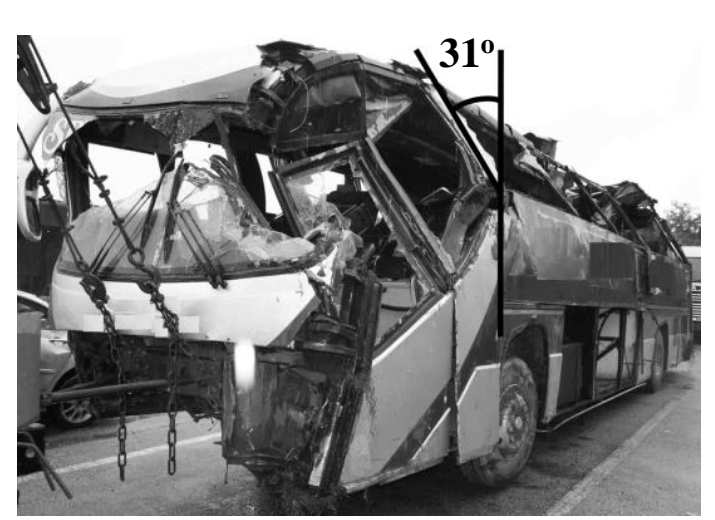

Figure 6(a) Case Study $1\left(D I_{\alpha}=0.69\right)$

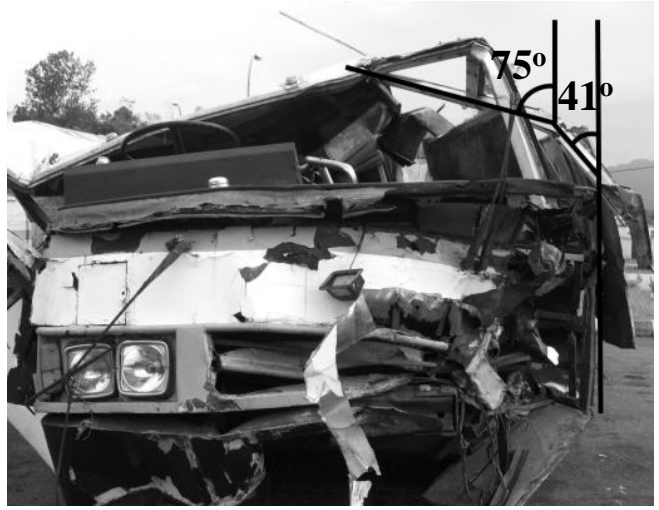

Figure 6(c) Case Study $3\left(D I_{\alpha}=-0.66\right)$

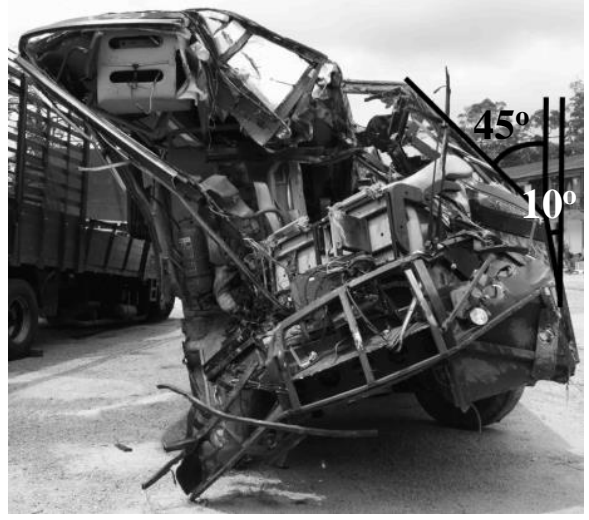

Figure 6(b) Case Study $2\left(D I_{\alpha}=2.00\right)$

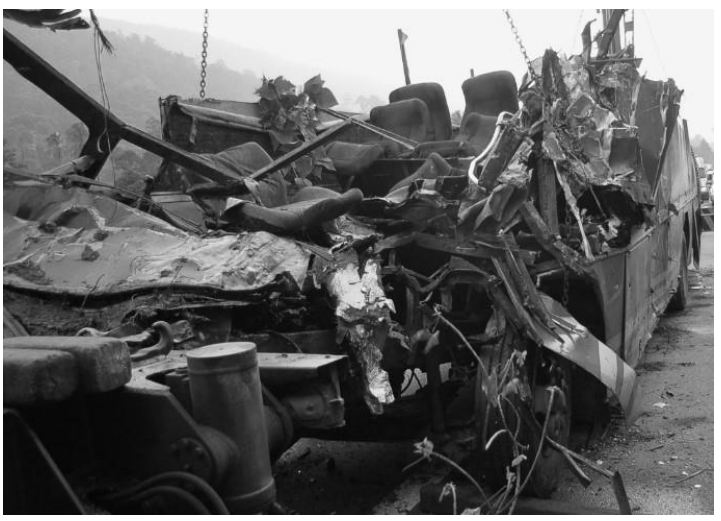

Figure 6(d) Case Study 4 (unknown $D I_{\alpha}$ )

Figure 6 Real bus rollover cases investigated in Malaysia, [8, 9 and 10]. 
In Figure 6(a), it shows Case Study 1 where the bus experienced rollover crash and the structure was deformed. Since the deformation was only at waistrail, the deformed angles were $\alpha_{1}=0^{\circ}$ and $\alpha_{2}=31^{\circ}$, respectively. Hence according to Eq.(1), $D I_{\alpha}$ of the structure is 0.69 . It means that the structure does not penetrate the residual space envelope. In Case Study 2 (Figure 6(b)), the deformed angle $\alpha_{1}$ was $10^{\circ}$ and $\alpha_{2}$ was $45^{\circ}$. This makes the $D I_{\alpha}$ of the structure to be 2.00 . The deformation was quite severe and it failed the 1.0 limit of $D I_{\alpha}$. It can be seen that the structure slightly penetrated into passengers' compartment. This may cause injury to the passengers. However, deformation in Case Study 3 (Figure 6(c)) was much severe as the roof was collapsed on the passengers' seats. The deformation angles are $41^{\circ}$ for $\alpha_{1}$ and $75^{\circ}$ for $\alpha_{2}$, which makes $D I_{\alpha}$ to be -0.66 , which is beyond the formula limit. Note that the skin and structure were badly corroded, worse than Case Study 1 and 2. In Figure 6(d), Case Study 4 shows the roof structure was totally detached from the main bus body. For this case, angular deformation index cannot be applied, hence $D I_{\alpha}$ is not applicable. For all four case studies discussed above, the value of $l, d$ and $h$ are assumed to be the same as in previous section $(788 \mathrm{~mm}, 400 \mathrm{~mm}$ and $1250 \mathrm{~mm}$, respectively) for the purpose of consistency. The deformation indices for all case studies mentioned above are summarized in Table 3.

Table 3 Deformation Index for Case Studies

\begin{tabular}{|c|c|c|c|}
\hline Case Study & $\boldsymbol{\Delta} \boldsymbol{\alpha}_{\mathbf{1}}$ (degree) & $\boldsymbol{\Delta \alpha _ { 2 } \text { (degree) }}$ & $\begin{array}{c}\text { Angular Deformation } \\
\text { Index, } \boldsymbol{D} \boldsymbol{I}_{\boldsymbol{\alpha}}\end{array}$ \\
\hline 1 & 0 & 31 & 0.69 \\
\hline 2 & 10 & 45 & 2.00 \\
\hline 3 & 41 & 75 & -0.66 (error) \\
\hline 4 & NA & NA & NA \\
\hline
\end{tabular}


Severe crash deformations shown in the above case studies are common, especially in the less developed countries. The main contribution to the structural failure is the ageing factor. Certain information is helpful to estimate the ageing effect on the bus structural strength, i.e.

- Record of bus mileage and road condition where the bus has operated can help the estimation of fatigue crack growth at bus structural points.

- If corrosion factor is to be considered, information on maintenance schedule and records are important, especially the information on the corrosion protection program. This is to determine how long the corrosion protection (e.g. painting) will protect the skin and structure of the bus from corrosion, and when the bus will expose to corrosion when its protection layer has completely diminished.

- Record on bus service area is also important to estimate corrosion rate applicable to the bus.

In practical, it is very difficult to obtain or retrieve the above information. This is due to multiple causes, e.g. lack of enforcement on standard regulations for bus operation, and poor maintenance and travelling records made by bus operators.

Besides ageing factors, some other uncontrolled variables may cause severe structural deformation. It is important to highlight these factors to differentiate the results of real rollover cases and simulated rollover cases under controlled environment. It gives much difference to the level of structural deformation and its severities. They are, among others:

- Design specification: At the design stage, designers may not consider safety aspects in building the bus structure. For example, continuous ring of the bus structure is more preferable compare to welded rings because welded joints are prone to crack and fail after a period of operation time. 
- Compliance to safety standard requirements: The awareness or willingness to look into safety aspects during design stage is related to the non-availability of safety requirements. For example, rollover test that follows standard regulation like UN R66 which is under discussion is not being introduced in Malaysia until year 2007. This leads to the fact that the manufacturers do not really pay attention to its compliance because it implicates extra costs to them.

- Velocity before impact: Some severe crashes investigated show that the bus was driven at a high speed exceeding the speed limit.

- Driver's qualification, experience and attitude: Problems like speeding and reckless driving are related to driver's qualification, experience and attitude. Some drivers are having invalid licenses, little experience in handling and driving heavy vehicles and poor driving attitude. This is also related to possible loose enforcement on traffic laws and road safety regulations.

- Over loading: Some buses are overloaded by carrying excessive passengers (and their luggage) than the respectively allowed passenger numbers and weight. For example, illegal adjustments on the number of seats were made to maximize the number of passengers.

- Crash configuration: When the crash is unavoidable, the bus driver normally tried his/her best to maneuver the bus before it gets the first impact. This leads to different combinations of impact direction e.g. frontal, side, and rollover. This cause the bus crashes in different ways and not simply deform at one side such as in the rollover test.

With large numbers bus rollover cases being investigated and recorded, the related variables can be retrieved and analyzed. This could give some significant values on the intended parameter, e.g. contribution of ageing towards bus structural strength. 


\section{Area and Volume Deformation Indices}

The Area Deformation Index $\left(D I_{A}\right)$ is introduced to objectively and linearly describe the deformation of a bus when the structure starts to penetrate into the residual space (i.e. in 'failed' region), up to a level where the bus structure is totally collapsed. This index can simply be described by using the percentage or ratio of residual space area being penetrated against its original residual space area. For example, Figure 7(a) shows a severely deformed finite element (FE) bus model with its residual space, while in Figure 7(b), the same deformed bus model but only the upper and side frames are shown together with its residual space. The most vulnerable frames are penetrated deepest into residual space area (i.e. the area covered by dashed lines which penetrates into residual space area). By manual calculation, it can be estimated that the intrusion is about $44 \%$ of the residual space cross-sectional area. Based on this calculation, the $D I_{A}$ is 0.44 . Thus, the bigger the $D I_{A}$ index value is, the worse the structural deformation would be. The minimum value of $D I_{A}$ index is 0.0 where no intrusion occurs (the bus passes the test); and maximum value is 1.0 , where the bus structure is $100 \%$ collapsed. In other words, as long as the residual space is secure, even though the structure might bend to some degree, $D I_{A}$ is still zero. 


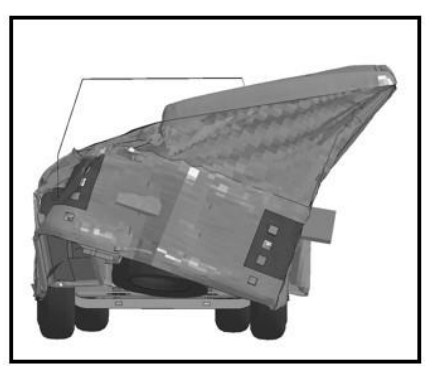

(a)

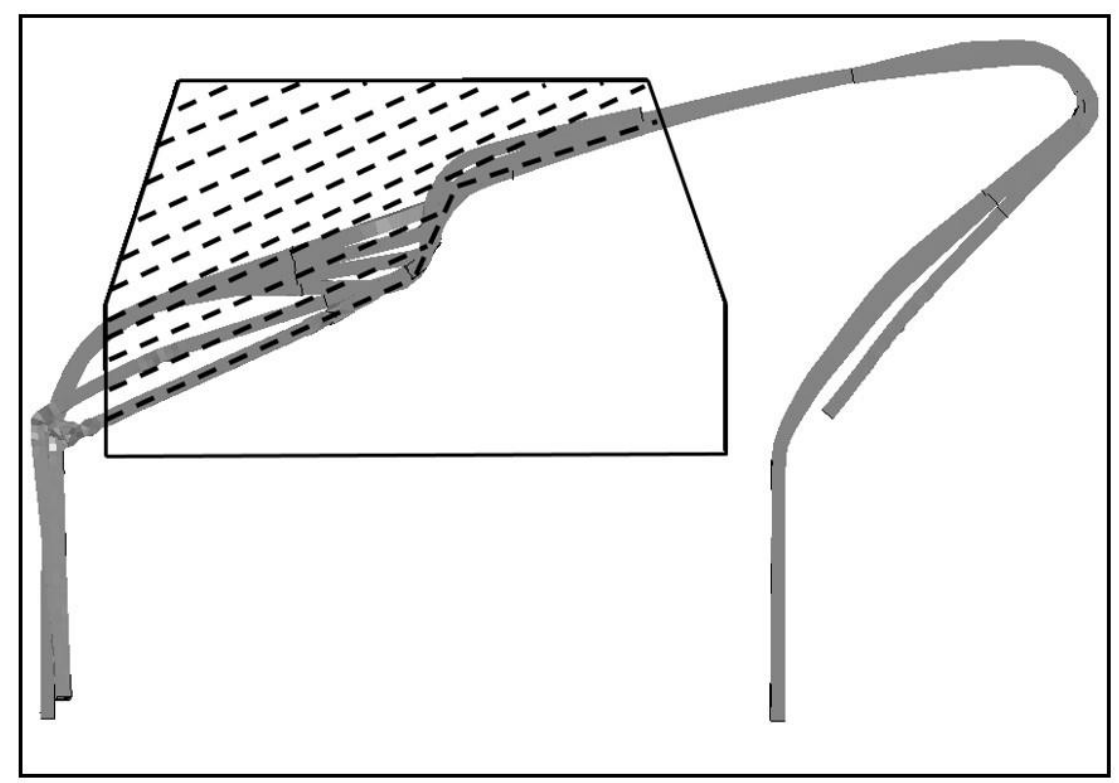

(b)

Figure 7 (a) Severely deformed bus (b) Upper and side frames of the bus intruded into residual space.

$D I_{A}$ is calculated as the residual area penetrated by the structure divided by residual space, i.e.

$$
D I_{A}=A_{S T} / A_{R S}
$$

where $A_{R S}$ is the residual space (area confined by trapezium shape) and $A_{S T}$ is the residual space area penetrated by the structure (area within the trapezium but covered by dashed lines).

If a graph of $D I_{A}=A_{S T} / A_{R S}$ is plotted, it shows a linear change as shown in Figure 8. 


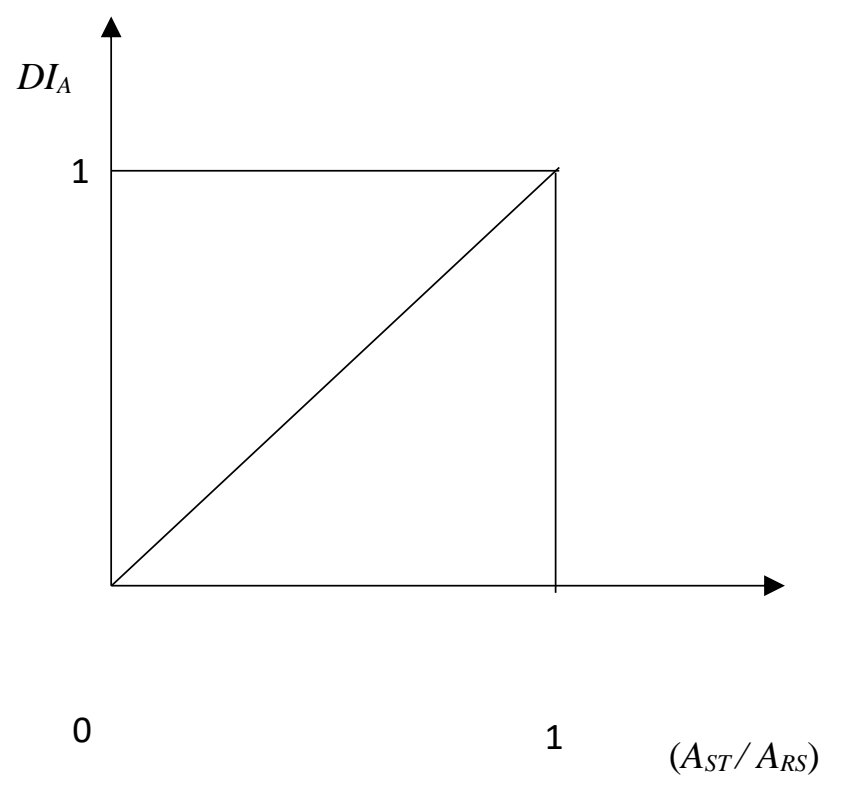

Figure 8 Graph of $D I_{A}=\left(A_{S T} / A_{R S}\right)$

It means that if $D I_{A}=0$, the residual space is secure and not being penetrated by the structure, and if $D I_{A}=1$, the structure is totally collapse and presumably created zero chance of survival of passengers. Since $D I_{A}$ is the ratio of the areas, it is non-dimensional. The following examples show how $D I_{A}$ can be used to measure severity of bus structural deformation.

\section{Example 1:}

In Figure 9, residual space has not been penetrated by the structure. In other words, the residual space envelope area, $A_{R S}$, which is the area confined by the dotted line, are not being penetrated by the structure. Therefore, penetrated area, $A_{S T}$ is zero. By using the proposed equation, $D I_{A}$ is 0.0 . 


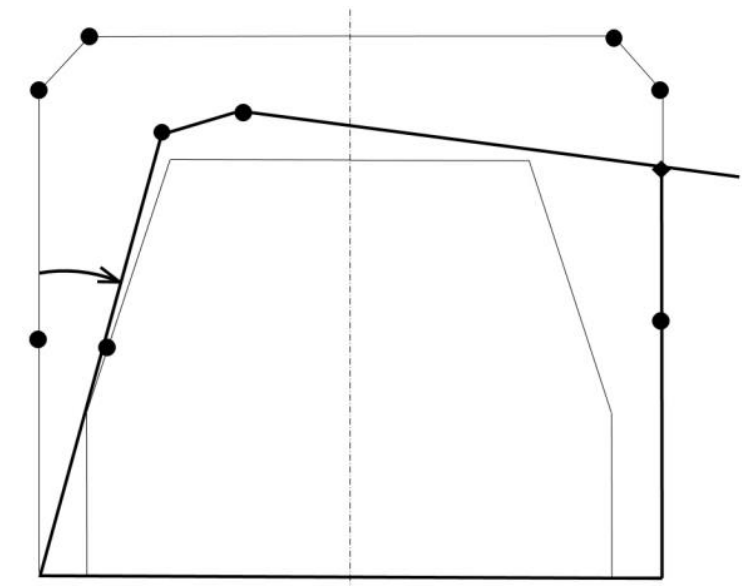

Figure 9 Residual space envelope not being penetrated $\left(D I_{A}=0.0\right)$

\section{Example 2:}

In Figure 10, residual space envelope was penetrated by the bus structure with reasonable depth. $A_{S T}$ is the area covered by non-continuous line. The penetrated area can be calculated, e.g. by using trapezium concept. Hence, Area Deformation Index for Example 2 is

$$
\begin{aligned}
D I_{A} & =\left(A_{S T} / A_{R S}\right) \\
& =0.39 .
\end{aligned}
$$

Therefore, residual space area penetrated by the structure is $39 \%$. 


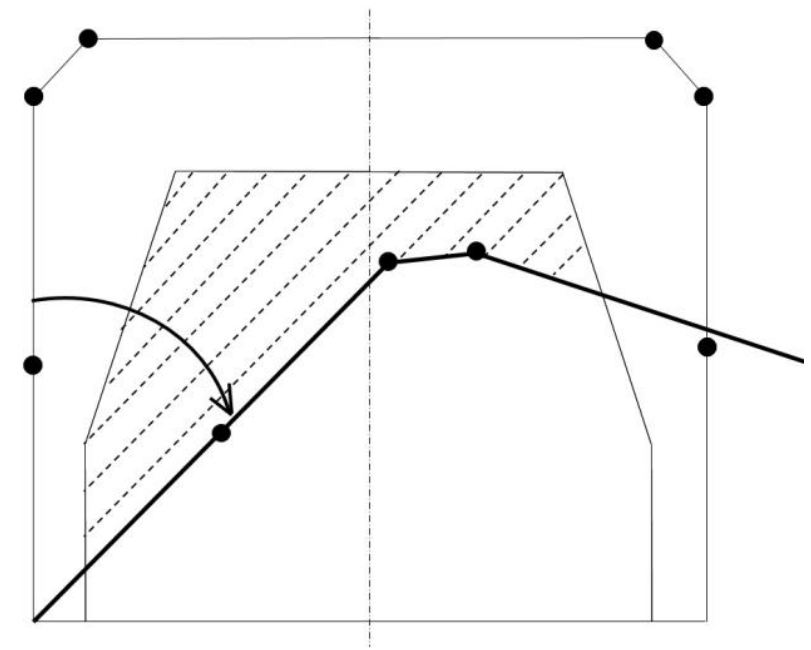

Figure 10 Residual space envelope being penetrated with $D I_{A}=0.39$

\section{Example 3:}

As shown in Figure 11, the deformation is very severe and can be considered as catastrophic. The condition is about the same as case study 3 (Figure 6(c)) where the structure is almost completely collapsed. By using the suggested equation, $D I_{A}$ for this example is 0.81 .

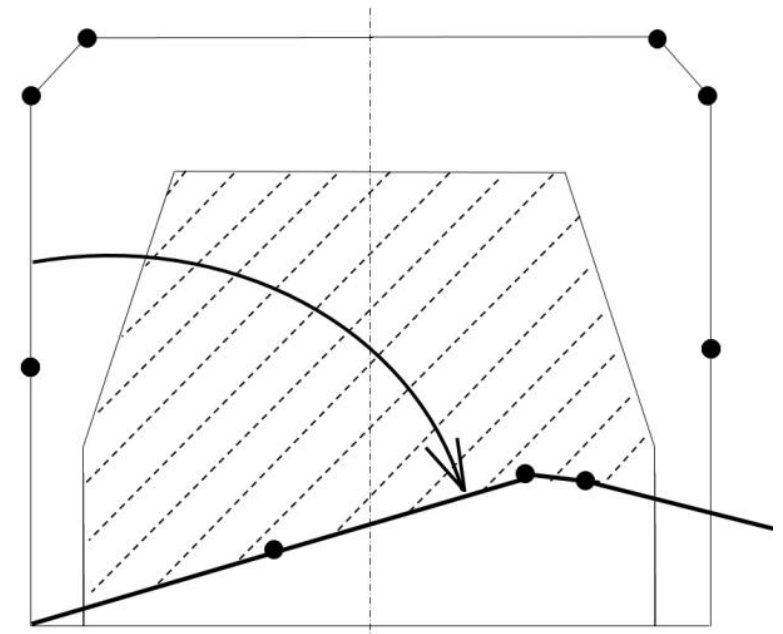

Figure 11 Catastrophic structural deformation $\left(D I_{A}=0.81\right)$ 
Based on Area Deformation Index $D I_{A}$, the severity of structural deformation can be measured and rated into several categories. The suggested categories of deformation severities are shown in Table 4 and the descriptive strength ratings of $D I_{\alpha}$ are also included in the table for comparison.

Table $4 D I_{\alpha}$ and $D I_{A}$ rating ranges and their descriptions

\begin{tabular}{|c|c|c|c|}
\hline $\boldsymbol{D I}_{\alpha}$ rating ranges & $\begin{array}{c}\text { Descriptive } \boldsymbol{D I} \boldsymbol{\alpha} \\
\text { strength rating }\end{array}$ & $\boldsymbol{D I}_{\boldsymbol{A}}$ rating ranges & $\begin{array}{c}\text { Descriptive } \boldsymbol{D I _ { \boldsymbol { A } }} \\
\text { severity rating }\end{array}$ \\
\hline$D I_{\alpha}<0.4$ & $\begin{array}{c}\text { Strong } \\
\text { Intermediate } \\
\text { Acceptable } \\
\text { Poor }\end{array}$ & $D I_{\alpha}<0.6$ & $\begin{array}{c}\text { Acceptable } \\
\text { (pass the test, but fail } \\
\text { if the structure touch } \\
\text { the residual space) }\end{array}$ \\
$0.6 \leq D I_{\alpha}<0.8$ & Inacceptable & $0.2<D I_{A} \leq 0.4$ & Weak \\
& & $0.4<D I_{A} \leq 0.6$ & Severe \\
& & $0.6<D I_{A} \leq 1.0$ & $\begin{array}{c}\text { Very severe } \\
\text { Catastrophic failure }\end{array}$ \\
\hline$D I_{\alpha} \geq 1.0$ & & &
\end{tabular}

If the comparison is made between $D I_{\alpha}$ and $D I_{A}$, it can be seen that $D I_{\alpha}$ specifies in detail the ratings on the deformation of the structure after the crash, which is from slight deformation to immediately before the structure touch the residual space. On the other hand, $D I_{A}$ focuses on ratings once the structure touches the residual space until the structure totally collapse.

Within the range of $D I_{A}$ index varies from 0.0 to 0.2 , the structure penetrates residual space at its early stage. It can be said that at this stage, occupants on the collapsed side are having high possibility experiencing injuries as the structure may already hit the head and upper body of occupants. But on the other side of the bus, the occupants may escape with no injuries as the residual space at that side is still intact. However, with index varies 0.6 to 1.0 , the structure is almost totally collapsed. At this stage, it can be said that all passengers are trapped inside the bus with high possibility of severe or fatal injuries. 
The suggested categories of severities of structural deformation rating can be linked to injury data, e.g. AIS. Information such as the occupants' location in the bus, and injury data, i.e. non-injuries, light injuries, severe injuries or fatal injuries of bus occupants due to rollover crash in real situation can be better or more accurately described and appreciated by comparing it to $D I_{A}$ and its rating. Location of structural section that is weaker or having more frequent crashes, e.g. frontal, middle, or rear can also be identified and analyzed. Furthermore, the effectiveness of residual space envelope can be evaluated and its definition or measurement can be changed if and when necessary. It is worth to note that survival or residual space defined in UN R66 is purely referring to the deformation of the bus structure due to rollover test and is not defined for the occupants, even though its upper dimensions does consider the height of the occupants when they sit. The same is applied in the discussion by [3]. For this reason, this paper also consider only the structural deformation and the residual space is not defined for the occupants. Hence, the occupants are assumed to be fully belted or they hold strongly to their seats during the crash. It is also assumed that the seats are perfectly attached to the bus floor.

To show the practicality of $D I_{A}$, case studies discussed in Section 3 are revisited. For case study 1, as shown in Figure 12(a), it can be illustrated in a simplified, cross-sectional two dimensional diagram as shown in Figure 12(b). It can be seen that the upper structure was deformed but was not penetrating the imaginary residual space. Hence, it does not fail both $D I_{\alpha}$ and $D I_{A}$, which are 0.69 and 0.0 , respectively. This crash caused one fatality and 28 injuries. These injuries are possibly due to factors other than structural deformation, e.g. unavailability of seatbelts, low seatbelts wearing or the seats detached from the bus floor. 


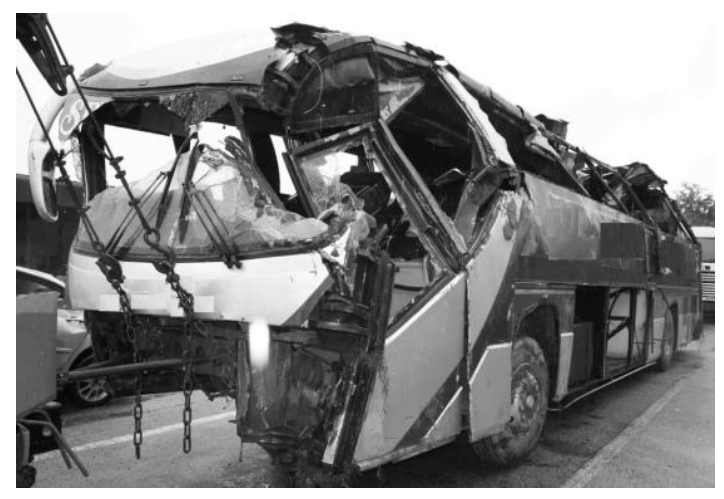

Figure 12(a) Case Study $1\left(D I_{A}=0.0\right)$

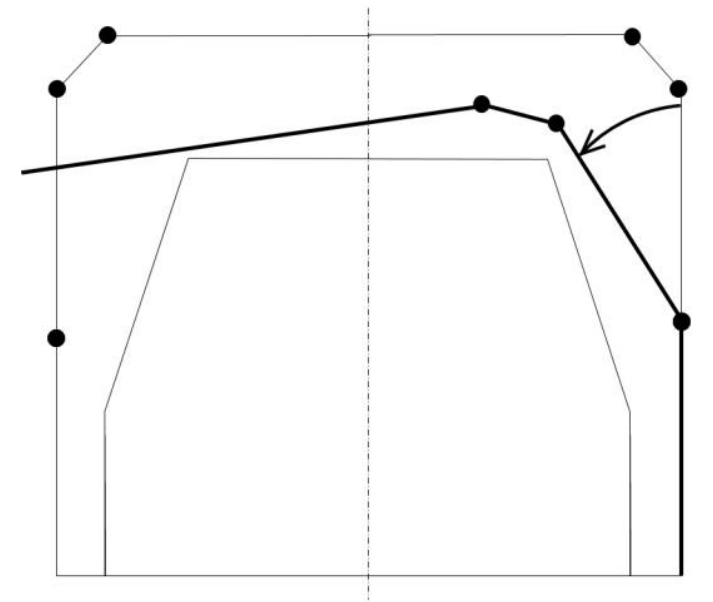

Figure 12(b) Cross-sectional diagram for Case Study 1 For case study 2 (Figures 13(a) and (b)), residual space was slightly penetrated by the structure. $D I_{\alpha}$ for this case is 2.00 while $D I_{A}$ is 0.04 . The structure is considered as weak in term of Area Deformation Index. From the photo, it can be seen that the structure may hit the upper body of passengers who seat next to the windows. In other words, a weak structure as described by $D I_{A}$ indicates high possibilities of injuries of the passengers next to windows. During the crash, the bus carried three passengers and one driver. The crash caused two fatalities, one severe injury and one light injury. The number of casualties is expected to be much higher if more passengers are in the bus, judging from the deformation experienced by the bus.

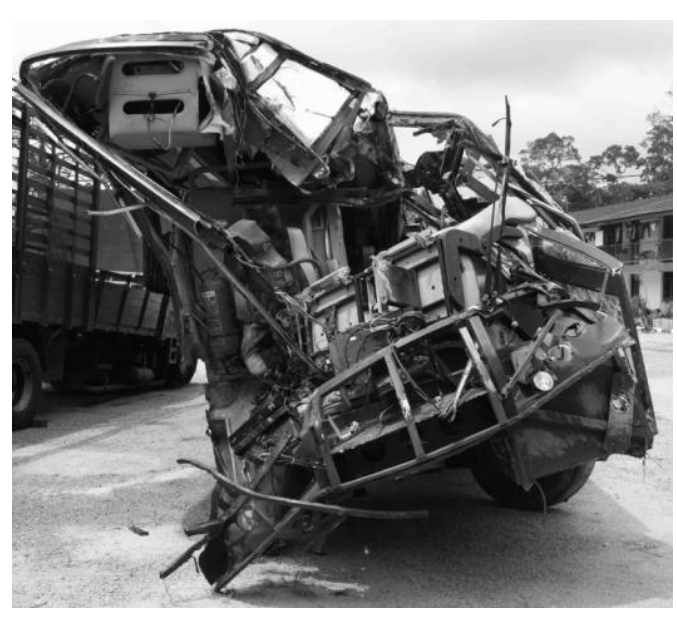

Figure 13(a) Case Study $2\left(D I_{A}=0.04\right)$

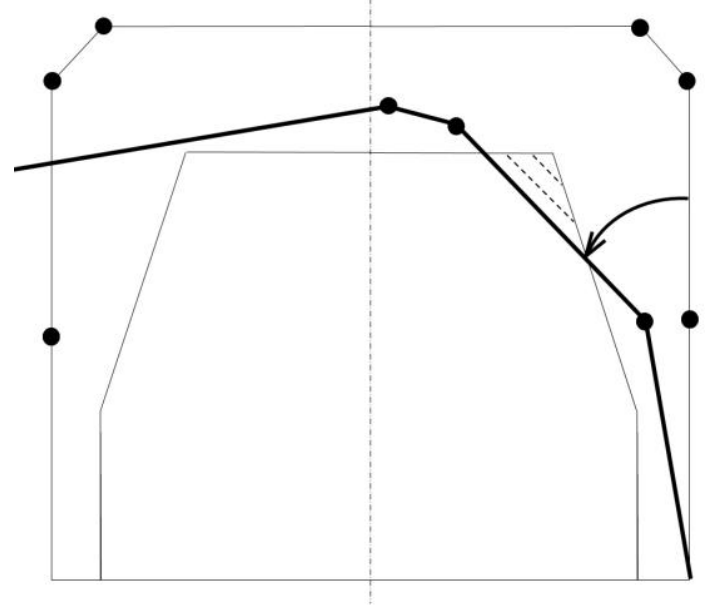

Figure 13(b) Cross-sectional diagram for Case Study 2 
Case study 3 (Figures 14(a) and (b)) shows a catastrophic failure on the superstructure of the bus. $D I_{\alpha}$ for this case is -0.66 , which is beyond the formula limit. $D I_{A}$ for this case is 0.62 which is classified as catastrophic. The diagram shows that the structure is collapsed up to the location near to the seat level. The Area Deformation Index indicates that all the passengers in the bus were most probably hit or trapped by the bus structure and they may experience severe or fatal injuries. The crash resulted in six fatalities and 25 injuries.

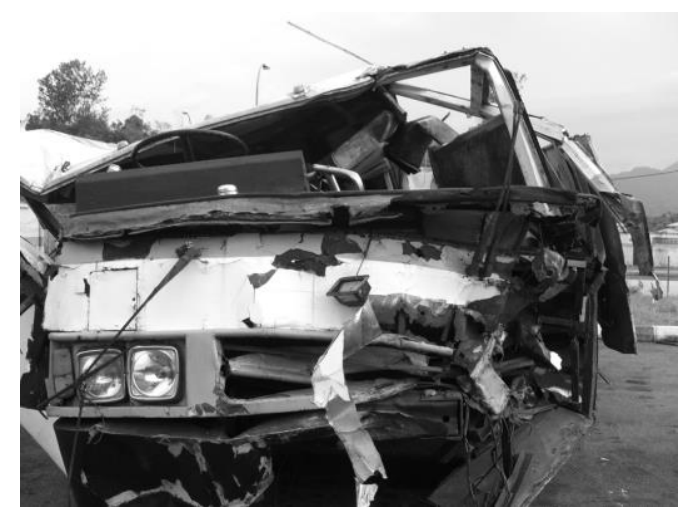

Figure 14(a) Case Study $3\left(D I_{A}=0.62\right)$

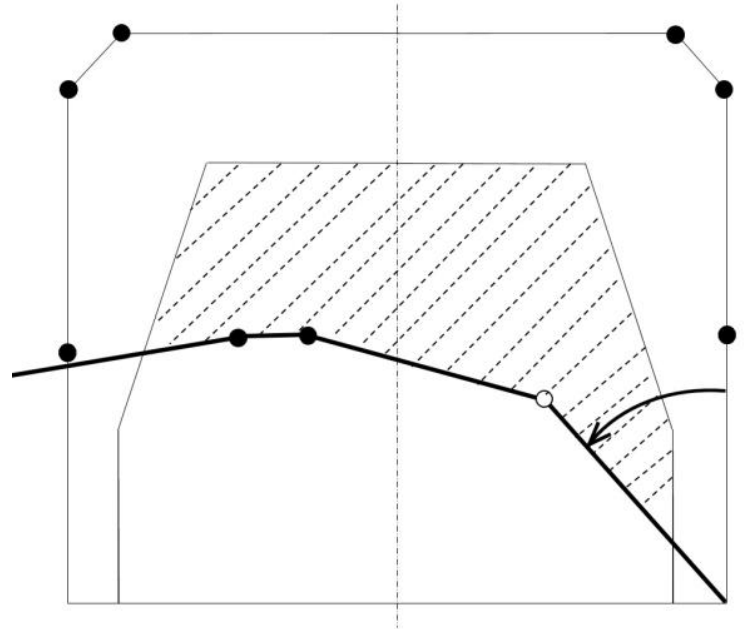

Figure 14(b) Cross-sectional diagram for Case Study 3

For case study 4 (Figure 15), $D I_{\alpha}$ is not applicable as the roof is totally detached from the main body. In this case, it can be assumed that the structure is totally collapse and leads to its detachment. Therefore, $D I_{A}$ is considered as 1.0. This crash killed 22 passengers while nine others sustained injuries. High number of fatalities may be due to head injuries because of the impact with the roof. 


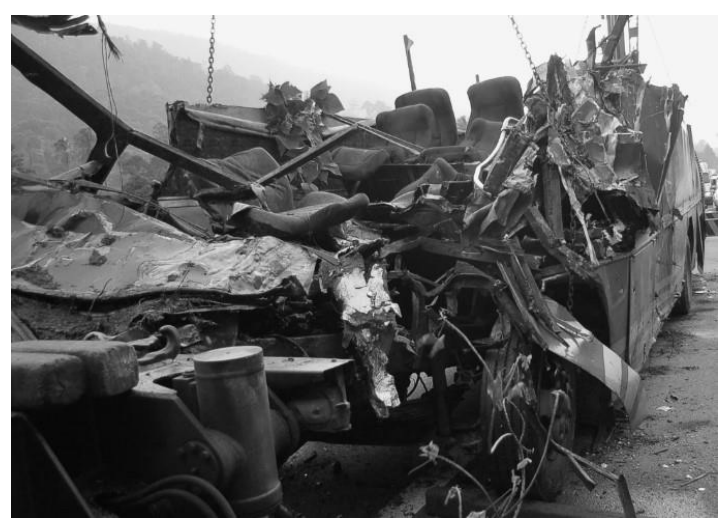

Figure 15 Case Study $4\left(D I_{A}=1.0\right)$

Note that the area of the structure and the area of residual space are all estimated based on available photos. The accurate measurements can be done by visual and physical checks at site. Table 5 compares the results for the case studies in terms of $D I_{\alpha}$ and $D I_{A}$ indexes and their respective descriptive strength rating or severe rating.

Table $5 D I_{\alpha}$ and $D I_{A}$ for Case Studies

\begin{tabular}{|c|c|c|c|c|}
\hline $\begin{array}{c}\text { Case } \\
\text { Study }\end{array}$ & $\begin{array}{c}\text { Angular Deformation } \\
\text { Index, } \boldsymbol{D I}_{\boldsymbol{\alpha}}\end{array}$ & $\begin{array}{c}\text { Descriptive } \boldsymbol{D} \boldsymbol{I}_{\boldsymbol{\alpha}} \\
\text { strength rating }\end{array}$ & $\begin{array}{c}\text { Area Deformation } \\
\text { Index, } \boldsymbol{D I}_{\boldsymbol{A}}\end{array}$ & $\begin{array}{c}\text { Descriptive } \boldsymbol{D} \boldsymbol{I}_{\boldsymbol{A}} \\
\text { severity rating }\end{array}$ \\
\hline 1 & 0.69 & Acceptable & 0.0 & Acceptable \\
\hline 2 & 2.00 & Inacceptable & 0.04 & Weak \\
\hline 3 & -0.66 & (Error) & 0.62 & Catastrophic failure \\
\hline 4 & $\mathrm{NA}$ & Inacceptable & 1.0 & Catastrophic failure \\
\hline
\end{tabular}

$D I_{A}$ is representing the severity index of bus deformation in two dimensions. In the real situation however, bus deformations may not always be uniform because of the varieties of rollover crash configurations. Because of the non-uniformity, $D I_{A}$ may not describe the real three-dimensional deformation severity for the whole bus. In such case, it is suitable to calculate the volume of 
structural intrusion against volume of residual space. This can also be turned into index and referred to as Volume Deformation Index $\left(D I_{V}\right)$.

As explained previously, residual space is an imaginary safety space to be preserved in the compartments to provide better survival possibility for the occupants in a rollover accident. By considering the space as defined in UN R66, it is in fact an imaginary volume in the bus compartments. Figure 16(a) shows the sample of volume of residual space, while in Figure 16(b), the residual space is defined in the bus. Figure 16(c) shows the residual space being penetrated by the deformed bus due to rollover. In Figure 16(d), it represent the same bus but only the residual space and upper structure of the bus are shown. The type of failure of this bus, as described in [2], is basic failure mode II where the plastic hinges developed at RF and at the waistrail level causing the structure to touch the upper section of residual space.

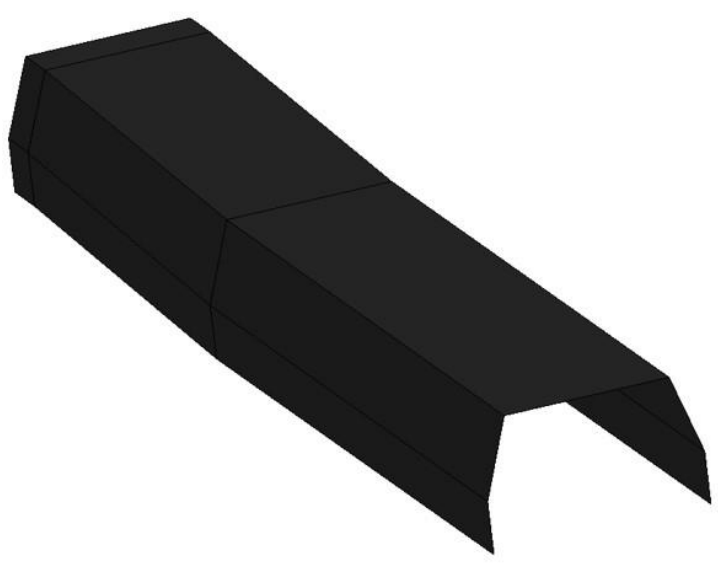

Figure 16(a) Residual space

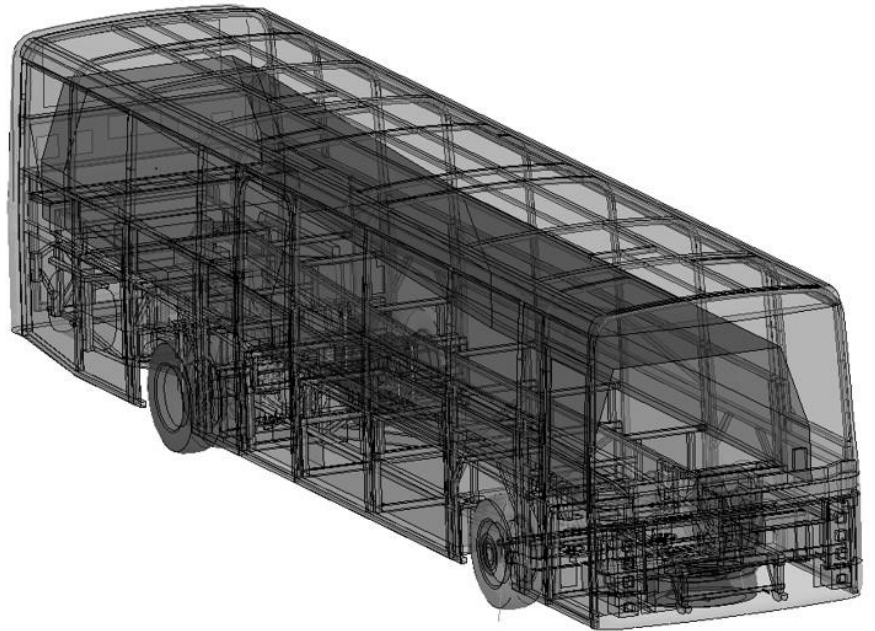

Figure 16(b) Residual space in a bus 


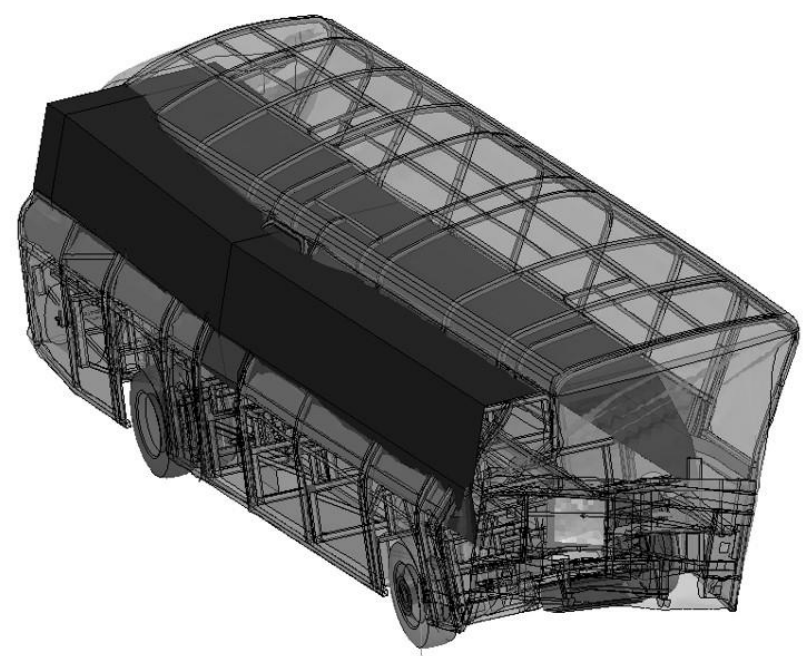

Figure 16(c) Residual space in a deformed bus

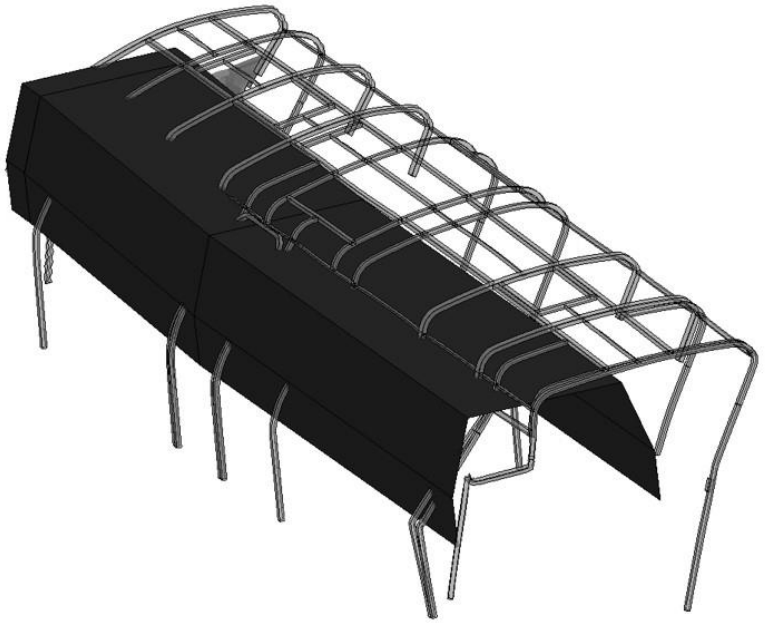

Figure 16(d) Residual space penetrated by bus structure

Figure 16 Residual space as an imaginary volume in a bus compartments

If the level of intrusion is examined by cross sections of the frontal and rear views, by manual calculations, the penetrations are about $14.3 \%$ at the front (Figure 17(a)) and $7.3 \%$ at the rear (Figure 17(b)). Therefore, the percentage of the structural intrusion into residual space can be estimated as $10.8 \%$. This, in Volume Deformation Index, is 0.11.

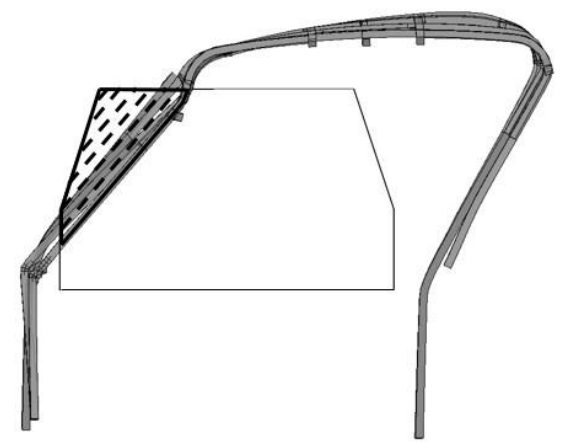

Figure 17(a) Frontal view of the deformed bus

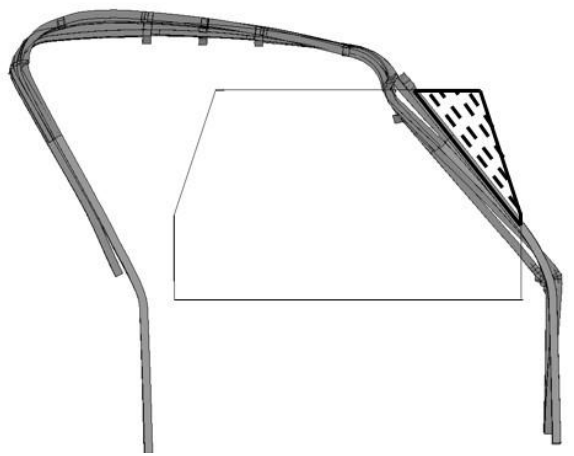

Figure 17(b) Rear view of the deformed bus

$D I_{A}$ and $D I_{V}$ indices are only estimations and require manual measurement and calculation. This can always be improved by using latest technological methods and software to accurately calculate 
the area and volume of the intrusion against the residual space. Among available technologies that can be used to serve the purpose is laser scanning method, for example in [11]. By using the laser scanning system, the crushed or deformed vehicle can be accurately measured to within the accuracy of millimeters. The documentation of vehicle's exterior and interior geometries using this device provides detailed 3D model of the vehicle, minimizes errors if the measurements were made by hand, and avoids tedious methods, e.g. using purposely designed jigs.

\section{Conclusions}

Bus rollover causes the deformation of its body structure. In rollover test, the deformation can be measured using $D I_{\alpha}$ index, until it fails the test. However, if the deformation is severe and the structure deeply penetrates into residual space envelope, $D I_{\alpha}$ is no longer suitable. This is true especially for real rollover crashes. A new index, termed as Area Deformation Index $\left(D I_{A}\right)$, is proposed to accurately measure the severity of deformation starting from early penetration stage of the structure into residual space envelope until the total collapse of the bus structure. If the structural deformation is not uniform throughout the bus body, Volume Deformation Index $\left(D I_{V}\right)$ can be used in the same way to measure the severity. Structural deformation severity for a bus undergoing rollover crash can be measured and rated into several categories, from weak to catastrophic levels. These index categories can be linked with injury data, e.g. AIS, to relate the injury severity with bus structural deformation, and to assess effectiveness of residual space envelope concept and dimensions. Several real case studies are discussed to show that the proposed concept is practical and the $D I_{A}$ index is more representative under real crash conditions and more relevant to fatality results. 


\section{References}

1. Peters GA, Peters BJ. Automotive Vehicle Safety. London: Taylor \& Francis; 2002. 19 p.

2. Bojanowski C. Verification, Validation and Optimization of Finite Element Model of Bus Structure for Rollover Test. [Thesis (PhD)]. Florida: Florida State University; 2009.

3. United Nations Economic Commission for Europe. Uniform Technical Prescriptions concerning the approval of large Passenger Vehicles with Regard to the Strength of Their Superstructure. United Nations; 2006 [cited 2017 April 4]. Available from: https://www.unece.org/fileadmin/DAM/trans/main/wp29/wp29regs/r066r1e.pdf.

4. Gepner BD. Rollover Procedures for Crashworthiness Assessment of Paratransit Bus Structures. Florida: Florida State University; 2014.

5. Deshmukh PS. Rollover and Roof Crush Analysis of Low-floor Mass Transit Bus. [Thesis (MSc)]. Wichita: Wichita State University; 2006.

6. Society of Automotive Engineers. Collision Deformation Classification. SAE International. 2011; J224_201105.

7. Association for the Advancement of Automotive Medicine [Internet]. Abbreviated Injury Scale. Chicago: AAAM. [cited 2017 April 4]. Available from: http://www.aaam.org/aboutais.html.

8. Azhar H, Abdul Rahmat AM, Mohd Huzaifah M, Mohd Syazwan S, Wong SV. Heavy Commercial Passenger Vehicle Service Life in Malaysia [Internet]. 2012 [cited 2017 April 4]; MRev 01/2012: [52p], Available from: https://www.miros.gov.my/1/publications.php?id_page=19\&id_event=50

9. Malaysian Institute of Road Safety Research (MIROS). In-depth Crash Investigation Database [unpublished data]. Malaysia: MIROS; 2017. 
10. Solah MS, Ariffin AH, MD Isa MH, Wong SV. In-depth Crash Investigation on Bus Accidents in Malaysia. Journal of Society for Transportation and Traffic Studies (JSTS); 2011.

11. Precisions Simulation. Vehicle Crush Analysis with laser Scanning. [updated 2015

October 20; cited 2017 April 4]. Available from:

http://www.precisionsim.com/index.php/blog/2015/10/vehicle-crush-analysis-laserscanning/

\section{Appendix 1: List of Figures}

Figure $1 \quad$ (a) \& (b) Lateral and (c) longitudinal arrangements of residual space (unit is in $\mathrm{mm})$

Figure 2 The path of the centre of gravity is shown through the starting and unstable equilibrium positions of the bus during rollover (unit is in $\mathrm{mm}$ )

$\begin{array}{ll}\text { Figure } 3 & \text { (a) Angles in the bus cross-section, and (b) geometry of the failure mode (unit is }\end{array}$ in $\mathrm{mm}$ )

Figure $4 \quad$ Angular Deformation Index versus deformation angles, $\alpha_{1}$ and $\alpha_{2}$

Figure 5
(a) $\Delta \alpha_{1}=0^{\circ}, \Delta \alpha_{2}=0^{\circ}, \Delta \alpha^{\prime}{ }_{1}=0^{\circ}, \Delta \alpha_{2}^{\prime}=0^{\circ}$,
(b) $\Delta \alpha_{1}=18^{\circ}, \Delta \alpha_{2}=18^{\circ}, \Delta \alpha^{\prime}{ }_{1}=$
$34^{\circ}, \Delta \alpha_{2}^{\prime}=34^{\circ}$,
(c) $\Delta \alpha_{1}=0^{\circ}, \Delta \alpha_{2}=39^{\circ}, \Delta \alpha^{\prime}{ }_{1}=0^{\circ}, \Delta \alpha^{\prime}{ }_{2}=43^{\circ}$

Figure 6 Real bus rollover cases investigated in Malaysia

Figure 6(a) Case Study $1\left(D I_{\alpha}=0.69\right)$

Figure 6(b) Case Study $2\left(D I_{\alpha}=2.00\right)$

Figure 6(c) Case Study $3\left(D I_{\alpha}=-0.66\right)$

Figure 6(d) Case Study 4 (unknown $D I_{\alpha}$ ) 
$\begin{array}{ll}\text { Figure } 7 & \text { (a) Severely deformed bus (b) Upper and side frames of the bus intruded into }\end{array}$ residual space

Figure $8 \quad$ Graph of $D I_{A}=\left(A_{S T} / A_{R S}\right)$

Figure 9 Residual space envelope not being penetrated $\left(D I_{A}=0.0\right)$

Figure 10 Residual space envelope being penetrated with $D I_{A}=0.39$

Figure $11 \quad$ Catastrophic structural deformation $\left(D I_{A}=0.81\right)$

Figure 12(a) Case Study $1\left(D I_{A}=0.0\right)$

Figure 12(b) Cross-sectional diagram for Case Study 1

Figure 13(a) Case Study $2\left(D I_{A}=0.04\right)$

Figure 13(b) Cross-sectional diagram for Case Study 2

Figure 14(a) Case Study $3\left(D I_{A}=0.62\right)$

Figure 14(b) Cross-sectional diagram for Case Study 3

Figure $15 \quad$ Case Study $4\left(D I_{A}=1.0\right)$

Figure 16 Residual space as an imaginary volume in a bus compartments

Figure 16(a) Residual space

Figure 16(b) Residual space in a bus

Figure 16(c) Residual space in a deformed bus

Figure 16(d) Residual space penetrated by bus structure

Figure 17(a) Frontal view of the deformed bus

Figure 17(b) Rear view of the deformed bus

\section{Appendix 2: List of Tables}

Table 1 Summary of aged bus rollover cases involving fatalities and injuries in Malaysia

Table 2 Rating ranges of angular deformation Index, $D I_{\alpha}$ 
Table 3 Deformation Index for Case Studies

Table $4 \quad D I_{\alpha}$ and $D I_{A}$ rating ranges and their descriptions

Table $5 \quad D I_{\alpha}$ and $D I_{A}$ for Case Studies

\section{Appendix 3: List of notation}

The following symbols are used in this paper:

ADR Australian Design Rule

AIS Abbreviated Injury Scale

CDC Collision Deformation Classification

CG Centre of Gravity

$D I_{A} \quad$ Area Deformation Index

$D I_{V} \quad$ Volume Deformation Index

$D I_{\alpha} \quad$ Angular Deformation Index

ERT Equivalent Rollover Testing

FMVSS Federal Motor Vehicle Safety Standards

$\mathrm{RF} \quad$ roof to wall

SAE Society of Automotive Engineers

UN R66 United Nations Regulation No. 66

VLCP Vertical Longitudinal Central Plane

WF wall to floor

$\Delta \alpha_{1} \quad$ Changes of wall to floor (WF) connections angles

$\Delta \alpha_{2} \quad$ Changes of waist rail (the structural part below the side windows) angles 